Check for updates

London, UK

Cite this as: BMJ 2020;369:m2462 http://dx.doi.org/10.1136/bmi.m2462 Published: 18 June 2020

\section{NHS health checks should start at age 25 for BAME patients, MPs hear}

\section{Adrian O'Dowd}

The NHS could help prevent illness and reduce the risk of contracting the coronavirus in patients from black, Asian, and minority ethnic (BAME)

backgrounds by lowering the age at which the NHS health check begins for some patients, MPs have been told.

MPs on the parliamentary women and equalities committee held an evidence session on 17 June for their inquiry into the impact of coronavirus on BAME people, who have been disproportionately dying from covid-19.

They asked medical and academic experts as well as those from BAME backgrounds if biological determinants were a primary factor in more BAME people dying from covid-19, and in which areas the government's efforts to protect BAME people would best be focused.

Kamlesh Khunti, professor of primary care diabetes and vascular medicine at the University of Leicester, giving evidence, said, "The biological factors are well known. There are some modifiable and some non-modifiable factors. Having chronic diseases is definitely a modifiable factor."

He referred to a matter dealt with in a Public Health England report ${ }^{1}$ on this subject published on 16 June, saying, "Primary prevention is key. We need to ensure that people from BAME backgrounds are assessed regularly for the risk factors that are mentioned.

"We have an NHS health check which is for people aged 40 to 74 . For people with BAME backgrounds, because they get these conditions earlier, we should extend that to age 25 and onwards."

There was also a need to target more help for BAME people in primary care, he added, saying, "We've had a lockdown for three months and this may continue for a little longer. There's been disruption in terms of managing patients in primary care practices.

"It's estimated that $95 \%$ of patients are managed in general practice. Because these people haven't had an assessment we need to ensure that they are seen early and their risk factors are controlled through remote consultations, which is happening but not routinely.

"When we come out of lockdown, we need to make sure that these people are assessed, they have their blood tests done, and they are managed more aggressively to make sure their risk factors are controlled."

Fellow witness Chaand Nagpaul, chair of council at the BMA, said that the BMA had been fighting for steps to be taken on this matter from the early stages of the pandemic, asking the government to investigate the fact that the first 10 doctors to die from covid-19 were all from a BAME background.

"The impact on healthcare workers has been severe," said Nagpaul. "We now know that $63 \%$ of healthcare workers who have died have come from a BAME background.

"From the outset, the BMA was calling for mitigations in terms of risk assessments and looking at ethnicity as a risk factor in its own right.”

The MPs asked to what extent the disproportionate number of BAME people dying from coronavirus was because of the nature of the virus itself, comorbidities, or socioeconomic factors.

Nagpaul said, "The matter of race and ethnicity is interlinked with many other risk factors and

“We know, for example, that you've got twice as much likelihood of dying if you come from a deprived community compared with a more affluent one and we also know that there's twice as many BAME people who live in deprived areas.

"There probably are race inequalities that have led to a greater proportion of BAME people living with low wages, working in those key roles, that could not allow them the same protection as those who were able to work at home."

Witnesses also said that face coverings should be mandatory in any workplace with BAME staff, if social distancing was impossible.

Nagpaul said, "Employers should ensure social distancing in the first instance and if that's not possible, they need to make sure there are screens or face coverings being employed as a means of reducing transmission.”

lacobucci G. Covid-19: Racism may be linked to ethnic minorities' raised death risk, says PHE. BMJ2020;369:m2421doi: 10.1136/bmj.m2421. inequalities. 